Uta Griesenbach July 2008

\title{
The role of doxorubicin in non-viral gene transfer in the lung
}

Uta Griesenbach ${ }^{1}$, Cuixiang Meng ${ }^{1}$, Raymond Farley ${ }^{1}$, Aaron Gardner ${ }^{1}$, Maresa

Brake $^{1}$, Gad M Frankel ${ }^{2}$, Dieter Gruenert ${ }^{3}$, Seng H Cheng ${ }^{4}$, Ronald K Scheule ${ }^{4}$, Eric WFW Alton ${ }^{1}$

${ }^{1}$ Department of Gene Therapy, Imperial College at the National Heart and Lung Institute, London UK and the UK Cystic Fibrosis Gene Therapy Consortium

${ }^{2}$ Division of Cell and Molecular Biology, Imperial College London, London SW3 6LR, UK

${ }^{3}$ California Pacific Medical Center Research Institute, San Francisco, CA 94107, Department of Laboratory Medicine, University of California, San Francisco, San Francisco, CA 94143, Department of Medicine, University of Vermont School of Medicine, Burlington, VT 05405

${ }^{4}$ Genzyme Ltd, Haverhill, UK

Correspondence should be addressed to:

Dr Uta Griesenbach

Department of Gene Therapy

Imperial College London

Manresa Road

London SW3 6LR, UK

Tel: $\quad 44(0) 2073518339$

Fax: $44(0) 2073518340 \quad$ Email: u.griesenbach@imperial.ac.uk

Short title: Doxorubicin increases non-viral gene transfer 
Uta Griesenbach July 2008

\section{Abstract}

Proteasome inhibitors have been shown to increase adeno-associated virus (AAV)mediated transduction in vitro and in vivo. To assess if proteasome inhibitors also increase lipid-mediated gene transfer with relevance to cystic fibrosis (CF), we first assessed the effects of doxorubicin and N-acetyl-L-leucinyl-L-leucinal-L-norleucinal in non-CF (A549) and CF (CFTE29o-) airway epithelial cell lines. CFTE29o- cells did not show a response to Dox or LLnL; however, gene transfer in A549 cells increased in a dose-related fashion $(\mathrm{p}<0.05)$, up to approximately 20 -fold respectively at the optimal dose (no treatment: $9.3 \times 10^{4} \pm 1.5 \times 10^{3}$, Dox: $1.6 \times 10^{6} \pm 2.6 \times 10^{5}$, LLnL: $1.9 \times 10^{6} \pm 3.2 \times 10^{5} \mathrm{RLU} / \mathrm{mg}$ protein). As Dox is used clinically in cancer chemotherapy we next assessed the effect of this drug on non-viral lung gene transfer in vivo. CF knockout mice were injected intraperitoneally (IP) with Dox (25 to 100 $\mathrm{mg} / \mathrm{kg}$ ) immediately before nebulisation with plasmid DNA carrying a luciferase reporter gene under the control of a CMV promoter/enhancer (pCIKlux) complexed to the cationic lipid GL67A. Dox also significantly $(\mathrm{p}<0.05)$ increased expression of a plasmid regulated by an elongation factor $1 \alpha$ promoter (hCEFI) approximately 8 -fold. Although administration of Dox before lung gene transfer may not be a clinically viable option, understanding how Dox increases lung gene expression may help to shed light on intracellular bottle-necks to gene transfer, and may help to identify other adjuncts that may be more appropriate for use in man.

Keywords: Lung, gene transfer, lipid, in vivo test, in vitro test 
Uta Griesenbach July 2008

\section{Introduction}

Proteasome inhibitors have been shown to increase adeno-associated virus (AAV)mediated transduction in vitro and in vivo (1-3). The exact mechanism remains unclear and does not appear to be related solely to the inhibition of vector degradation through the ubiquitin-proteasome degradation pathway. In contrast to viral transductions, the pathways involved in cell and nuclear entry of non-viral gene transfer agents, and movement of these complexes within the cell, are poorly understood and the contribution (if any) of proteasomes to this process remains unclear. Two studies have reported that proteasome inhibitors increased non-viral gene transfer in vitro $(4 ; 5)$.

$\mathrm{CF}$ is a chronic disease which will require treatment with gene transfer agents over the life-time of the patient. Problems associated with repeat administration of most viral vectors have been well described $(6 ; 7)$. Because of this, repeat administration of nonviral gene transfer agents is currently the most promising approach for the development of cystic fibrosis (CF) gene therapy. The cationic lipid GL67A (8) is, in our hands, the most efficient non-viral vector for lung transfections. GL67A consists of three components: (1) the cationic lipid GL67 [Cholest-5-en-3-ol (3ß)-,3-[(3aminopropyl)[4-[(3-aminopropyl)amino]butyl]carbamate], consisting of an amine (spermine) and a lipid (cholesterol) component linked together via a carbamate linker, (2) DOPE (1,2-dioleoyl-sn-glycero-3-phosphoethanolamine) a naturally occurring neutral lipid, (3) DMPE-PEG5000 (1,2-Dimyristoyl-sn-Glycero-3Phosphoethanolamine-N-[methoxy (Polyethyleneglycol)5000] which is 1,2dimyristoyl-sn-glycero-3-phosphoethanolamine linked to polyethylene glycol monomethylether (average molecular weight ca. 5000) via a carbamate linkage. To 
Uta Griesenbach July 2008

generate the gene transfer agent the three lipids are formulated at 1:2:0.05

(GL67:DOPE:DMPE-PEG5000) molar ratios and complexed to DNA (8). We have achieved partial correction of the chloride transport defect in the lungs of CF patients after GL67A-mediated gene transfer of plasmid DNA carrying the cystic fibrosis transmembrane conductance regulator (CFTR) cDNA (9). However, the efficiency of non-viral gene transfer is comparatively low compared to viral vectors, such as for example Sendai virus (10), and it is currently unclear, if non-viral gene therapy can ameliorate the chronic lung infection and inflammation that causes most morbidity and mortality in CF subjects. The clinical trial programme currently carried out by the UK CF Gene Therapy Consortium (www.cfgenetherapy.org.uk) aims to assess if GL67A-mediated CFTR gene transfer is able to ameliorate of CF lung disease. In parallel, however, we are investigating a variety of adjuncts that may further increase GL67A-mediated lung gene transfer as part of our pre-clinical development programme.

Here, we assessed if proteasome inhibitors could improve GL67A-mediated gene transfer in the mouse lung. Doxorubicin, an anthracyclin derivative, and N-acetyl-Lleucinyl-L-leucinal-L-norleucinal (LLnL), a tripeptide aldehyde inhibitor, have previously been shown to increase AAV-mediated gene transfer in vitro (11). Importantly, doxorubicin is in clinical use for cancer chemotherapy, and in support of our translational research programme, we chose this drug to determine, if proteasome inhibition increases non-viral gene transfer in the mouse lung in vivo. 
Uta Griesenbach July 2008

\section{Materials and Methods}

\section{In vitro transfection}

A549 cells, an adenocarcinoma cell line (ATCC, Manassas, USA) and a cystic fibrosis tracheal epithelial cell line (CFTE29o-) (12) were plated onto 6-well plates (100,000 cells/ well). Approximately $24 \mathrm{hr}$ later cells were transfected with the eukaryotic expression plasmids pCIKLux carrying a luciferase reporter gene under the control of the cytomegalovirus (CMV) immediate/early promoter $(1 \mu \mathrm{g} \mathrm{DNA} / \mathrm{well})$ or an irrelevant control plasmid carrying no reporter gene (pCIK-empty). Each was complexed to Lipofectamine 2000 (LF2000, Invitrogen, Paisley, UK) according to manufacturers recommendations for $6 \mathrm{hr}$. During this time cells were also exposed to various concentrations of doxorubicin (0.5-20 mM, Sigma-Aldrich, Poole, UK) dissolved in sterile water for injection or N-acetyl-L-leucinyl-L-leucinal-L-norleucinal (LLnL: 10-100 $\mu \mathrm{M}$, Sigma-Aldrich) dissolved in ethanol. After $6 \mathrm{hr}$ the medium was removed and replaced with fresh MEM medium containing 10\% FCS and 1\% ampicillin/streptomycin. Cells were harvested $48 \mathrm{hr}$ after transfection and resuspended in $500 \mu \mathrm{l}$ 1xRLB buffer (Promega, Southampton, UK) followed by three freeze/thaw cycles and centrifugation at $13,000 \mathrm{~g}_{\mathrm{av}}$ for $10 \mathrm{~min}$. The supernatant was frozen for quantification of luciferase expression.

\section{Mice}

Male and female C57B1/6, Balb/C mice (Charles River, UK) or gut-corrected CFknockout mice on a mixed genetic background (13) (bred in-house) were used at approximately 6-12 weeks of age (for details see Figure legends). All experiments were carried out with approval of the appropriate local Ethics Committee and according to Home Office regulations. 
Uta Griesenbach July 2008

\section{Doxorubicin administration in vivo}

Doxorubicin (Dox, Sigma Aldrich, Poole, UK) was dissolved in sterile water for injection to $5 \mathrm{mg} / \mathrm{ml}$ and administered intraperitoneally (IP) $(0-100 \mathrm{mg} / \mathrm{kg})$ immediately before gene transfer. IP injection of proteasome inhibitors has previously been shown to be effective in the context of AAV-mediated gene transfer. In some experiments Dox was administered topically to the lung using our standard "nasal sniffing" protocol. For this the mice were anaesthetised with isofluorane and a single $100 \mu \mathrm{l}$ bolus containing 125 to $500 \mu \mathrm{g}$ Dox (equivalent to 6 to $25 \mathrm{mg} / \mathrm{kg}$ ) was applied to the nose and rapidly sniffed into the lung. $25 \mathrm{mg} / \mathrm{kg}$ was the highest dose feasible for topical administration as mice showed signs toxicity above this concentration.

Caelyx $^{\circledR}(2 \mathrm{mg} / \mathrm{ml})$, a pegylated liposome encapsulated Dox formulation, was injected IP or intravenously (IV) immediately before gene transfer.

\section{In vivo transfection of murine lung}

The cationic lipid GL67A is a mixture of GL67 (Genzyme, Haverhill, UK), DOPE and DMPE-PEG5000 (Avanti Lipids, Alabama, USA) (8). The lipids were formulated and freeze-dried by OctoPlus N.V. (Leiden, The Netherlands) as previously described (8). pCIKLux or pG4-hCEFI-soLux, which is an advanced fourth generation plasmid carrying a CpG-depleted, codon optimised luciferase reporter gene regulated by a hybrid promoter consisting of the CMV enhancer and the elongation factor $1 \alpha$ promoter (14).

Nebulisation: Immediately after Dox administration mice were placed into an exposure chamber and exposed to an aerosol generated by a PARI LC + nebuliser 
Uta Griesenbach July 2008

(PARI GmbH, Starnberg, Germany) at a pressure of 22 psi for $1 \mathrm{hr}$. GL67A/pDNA complexes for aerosolisation were prepared as previously described (14). Briefly, 25 mg plasmid DNA ( $5 \mathrm{mg} / \mathrm{ml}$ ) were complexed with $5 \mathrm{ml} \mathrm{GL67A}$ to a final molar ratio of 6:8 in a total volume of $10 \mathrm{ml}$. Reporter gene expression was quantified $24 \mathrm{hr}$ after transfection to detect maximal levels of gene expression.

\section{Bioluminescence imaging}

D-Luciferin (Xenogen Corporation, Alameda, CA) was either administered IP (150 $\mathrm{mg} / \mathrm{kg}$ in $200 \mu \mathrm{l})$ or topically $(75 \mathrm{mg} / \mathrm{kg}$ in $100 \mu \mathrm{l})$, using our "nasal sniffing" protocol described above, to mice 10 min before imaging. Bioluminescence (photons s $\mathrm{sm}^{-1}$ $\mathrm{sr}^{-1}$ ) from living mice was measured using an IVIS50 system (Xenogen Corporation, Alameda, CA, USA) at a binning of 4, over 10 minutes, using the software programme Living Image (Xenogen). For anatomical localisation a pseudocolour image representing light intensity (blue least intense, red most intense) was generated using Living Image software and superimposed over the greyscale reference image. To quantify bioluminescence in the nose and right and left lungs photon emission in a defined area was measured by marking a standardized area for quantification.

\section{Tissue homogenate-based luciferase assay}

Mice were culled by cervical dislocation. The mouse lungs were harvested and frozen in liquid nitrogen. To extract luciferase protein lungs were placed in $100 \mu 1$ and 300 $\mu 1$ 1xRLB buffer (Promega), respectively. The lung was homogenized using a FastPrep homogenizer (Thermo Fisher Scientific, Waltham, MA, USA) set to $40 \mathrm{~m} / \mathrm{sec}$ for 45 seconds followed by $15 \mathrm{~min}$ incubation at room temperature. The supernatant was removed and transferred to a QiaShredder column (Qiagen, Crawley, Sussex) and 
Uta Griesenbach July 2008

centrifuged ( $1 \mathrm{~min}$ at $16,000 \mathrm{~g}_{\mathrm{av}}$ ) followed by an additional centrifugation ( $5 \mathrm{~min}$ at $\left.16,000 \mathrm{~g}_{\mathrm{av}}\right)$. Luciferase activity was measured in the supernatant using a standard luciferase assay kit (Promega) and the TD-20e luminometer (Turner, Sunnyvale, CA, USA). Total protein per sample was determined using the BioRad protein assay kit (BioRad laboratories, Hercules, CA) and luciferase activity was expressed as arbitrary relative light units (RLU)/mg total protein.

\section{Statistical analysis}

Statistical analyses were performed by ANOVA and Kruskal-Wallis followed by post-hoc analysis appropriate for parametric and non-parametric data. The null hypothesis was rejected at $\mathrm{p}<0.05$. 
Uta Griesenbach July 2008

\section{Results}

\section{Proteasome inhibitors in vitro}

To establish proof-of-principle, we first assessed the effects of proteasome inhibitors on Lipofectamine 2000-mediated (LF2000) gene transfer in two airway epithelial cell lines (A549 and CFTE29o- cells). Cells were exposed to various concentrations of Dox $(0.5-20 \mathrm{mM})$ and LLnL $(10-100 \mu \mathrm{M})$ for $6 \mathrm{hr}$ during transfection with pCIKLux complexed to LF2000. CFTE29o- cells did not show a response to Dox or LLnL (data not shown), but gene transfer in A549 cells increased in a dose-related fashion approximately 20 -fold respectively, at the optimal dose $(\mathrm{p}<0.05, \mathrm{n}=8 /$ group $)$ (Fig 1). We reproducibly observed a U-shaped dose-response with Dox.

\section{Doxorubicin effects in the murine lung}

To assess the effect of proteasome inhibitors on non-viral lung gene transfer in vivo CF knockout mice were injected intraperitoneally (IP) with Dox $(0,25,50$ and 100 $\mathrm{mg} / \mathrm{kg}, \mathrm{n}=8$ mice/group) immediately before nebulisation of pCIKlux complexed to the cationic lipid GL67A, and compared to animals transfected without Dox. CF knockout mice were used because we routinely use these for gene transfer studies and have a large in house breeding colony. Gene expression was analysed $24 \mathrm{hr}$ after gene transfer. Dox increased gene transfer in a dose-related fashion (Fig 2). Mice receiving the lowest dose $(25 \mathrm{mg} / \mathrm{kg})$ did not show an increase in luciferase expression, but in mice receiving 50 or $100 \mathrm{mg} / \mathrm{kg}$ luciferase was significantly (approximately 20-fold, $\mathrm{p}<0.05$ ) increased compared to no Dox administration. Administration of $100 \mathrm{mg} / \mathrm{kg}$ did not increase gene transfer compared to $50 \mathrm{mg} / \mathrm{kg}$, but toxicity was observed at this dose, with 1 out of 8 mice dying within the $24 \mathrm{hr}$ period and 4 out of 7 mice showing hunching and pilo-erection. In contrast all mice treated with $50 \mathrm{mg} / \mathrm{kg}$ dose were 
Uta Griesenbach July 2008

outwardly indistinguishable from mice not treated with Dox. Subsequent experiments were, therefore, carried out with a dose of $50 \mathrm{mg} / \mathrm{kg}$.

To assess reproducibility of the results the experiment was repeated using the optimal dose of $50 \mathrm{mg} / \mathrm{kg}$ Dox I.P. with higher n numbers showing reproducible results (Fig 3). Although we would not expect there to be difference between $\mathrm{CF}$ and non-CF mice, we also assessed the effects of Dox in wild-type Balb/C and C57B1/6 mice and consistently demonstrated a significant $(\mathrm{p}<0.05)$ increase in GL67A-mediated lung gene expression after IP Dox administration, respectively (Fig 3).

Since the optimal dose $(50 \mathrm{mg} / \mathrm{kg})$ is approximately 3 times higher than that used clinically, we attempted to increase the local concentration of Dox in the lung by administering the drug ( 6 to $25 \mathrm{mg} / \mathrm{kg}$ ) topically via nasal sniffing. However, this did not increase luciferase expression compared to mice receiving no Dox (data not shown).

\section{In vivo bioluminescence imaging}

We have previously shown that cationic lipid GL67A-mediated luciferase gene transfer can be detected with in vivo bioluminescence imaging (BLI) in lungs of mice following nasal "sniffing" of lipid/DNA complexes into the lung (15). However, nebulisation is generally less efficient than nasal "sniffing" and, as shown here, insufficient (only 2 out of 9 mice showed a weak signal) to allow BLI using standard I.P administration of the luciferin substrate (150 mg/kg) (Fig. 4a). Interestingly, we showed that (a) a significantly $(\mathrm{p}<0.001)$ stronger BLI signal can be visualised in 7 out of 9 mice after GL67A/pCIkLux nebulisation by administering the luciferin 
Uta Griesenbach July 2008

substrate topically $(75 \mathrm{mg} / \mathrm{kg}$ ) to the lungs of Balb/C mice by "nasal sniffing" instead of using the standard IP route (Fig. 4b) despite the fact that only half of the I.P dose was administered and that (b) IP administration of Dox $(50 \mathrm{mg} / \mathrm{kg})$ further significantly $(p<0.05)$ increased the BLI signal (Figs $4 c+d)$.

\section{Promoter-independent increase in gene expression}

In addition to the pCIKLux plasmid which is regulated by the immediate/early cytomegalovirus (CMV) promoter/enhancer, we also assessed the effects of Dox on a eukaryotic luciferase expression plasmid regulated by a hybrid promoter consisting of the CMV enhancer and the elongation factor $1 \alpha$ promoter (pG4-hCEFI-soLux). Similar to results obtained with pCIKLux, Dox significantly $(\mathrm{p}<0.005)$ increased pG4-hCEFI-soLux -mediated expression in Balb/C mice (Fig 5).

\section{Effects of Caelyx ${ }^{\circledR}$ on lung gene expression}

The most advanced Dox formulation currently in clinical use is a pegylated liposome encapsulated formulation $\left[\right.$ Caelyx $^{\circledR}(\mathrm{UK})$ or Doxil $^{\circledR}$ (USA)]. We, therefore, assessed the effects of Caelyx ${ }^{\circledR}$ on GL67A/pCIKLux-mediated lung gene transfer. We administered either $4,16.5$ or $40 \mathrm{mg} / \mathrm{kg}$ I.P to CF knockout mice ( $\mathrm{n}=8 /$ group) mice.

These doses were chosen because $16.5 \mathrm{mg} / \mathrm{kg}$ is equivalent to $50 \mathrm{mg} / \mathrm{m}^{2}$ body surface, the latter being dose used in man, and $40 \mathrm{mg} / \mathrm{kg}$ being equivalent to $400 \mu \mathrm{l}$ of a 2 $\mathrm{mg} / \mathrm{ml}$ solution, the maximum volume allowed for IP injection under Home Office license regulations. All mice tolerated the treatment well and were culled $24 \mathrm{hr}$ after gene transfer. IP administration of Caelyx ${ }^{\circledR}$ did not increase reporter gene expression in the lung (Fig 6a). 
Uta Griesenbach July 2008

For clinical use Caelyx ${ }^{\circledR}$ is administered intravenously (IV) and we, therefore, also assessed the effects of IV administration on lung gene expression. Caelyx ${ }^{\circledR}$ ( 4 or 20 $\mathrm{mg} / \mathrm{kg}$ ) was injected into the tail vein of mice immediately before nebulisation of GL67A/pCIKlux. The $20 \mathrm{mg} / \mathrm{kg}$, equivalent to $200 \mu 1$ of a $2 \mathrm{mg} / \mathrm{ml}$ solution, is the maximum volume allowed for IV injection under Home Office license regulations. All mice tolerated the treatment well and were culled $24 \mathrm{hr}$ after gene transfer. IV injection of Caelyx ${ }^{\circledR}$ modestly increased gene expression, but this did not reach significance $(\mathrm{p}=0.05)$ (Fig 6b). 
Uta Griesenbach July 2008

\section{Discussion}

Here, we show that proteasome inhibitors increase cationic lipid-mediated gene transfer in vitro and in murine lung in vivo. However, the clinically relevant agent doxorubicin shows a narrow efficacy-toxicity window, which was not improved by variations in route of administration. We conclude, it is unlikely that Dox will be suitable for clinically relevant gene therapy in CF patients.

Proteasome inhibitors have been shown to increase AAV-mediated gene transfer in various ex vivo and in vivo models of lung gene transfer, including air liquid interphase cultures, xenograft models and the murine lung $(3 ; 11)$. However, the mechanism is unclear; possibilities including (a) prevention of virus degradation, (b) improved nuclear uptake, (c) improved genome uncoating, (d) enhanced capsid processing, (e) improved second strand synthesis and (e) reduced degradation of the recombinant protein. The effect of proteasome inhibitors in the context of non-viral gene transfer has, to the best of our knowledge, only been described in two in vitro studies. Kim J et al reported that proteasome inhibitors increased non-viral peptidemediated gene transfer and Kim KI et al showed that doxorubicin increases lipidmediated gene transfer $(4 ; 5)$.

In our hands the benefits of LLnL and doxorubicin on non-viral gene transfer in vitro were cell type specific. Although A549 cells, an adenocarcinoma cell line with type II cell characteristics responded to both proteasome inhibitors with a 20-30 fold increase in gene expression, the drugs did not increase gene expression in CFTE29o- cells, derived from tracheal epithelium of a CF subject. In the context of AAV transduction A549 cells also responded to LLnL and doxorubicin (11) whereas as shown by Kim et 
al (4) proteasome inhibitors did not increase LF2000-mediated gene transfer in CF/T1 cells, another CF airway epithelial cell line. Similarly Yan et al showed that the response to LLnL varies in different airway cell lines when transduced with AAV (11). It is unlikely that the unresponsiveness of CFTE29o- cells to proteasome inhibitors is due to the CF genotype of these cells, because we also demonstrated that non-viral gene transfer in both CF-knockout mice and non-CF mice responded similarly to Dox pre-treatment.

Although doxorubicin treatment increased non-viral gene transfer by up to 20 -fold these levels in our experience are still too low to allow detection of recombinant protein with immunohistochemistry or X-gal-based methods. Thus, we are currently unable to determine which cells have been transduced and if the number of cells expressing the recombinant protein, or the amount of protein per cell, increased in response to doxorubicin treatment. This question is also difficult to address in the existing AAV studies. Although the number of reporter gene expressing cells increased in response to proteasome inhibition, it is unclear if negative cells were untransduced, or if cells were transduced but levels of reporter gene expression were below the detection limit of the assay (2). Kim et al suggested that proteasome inhibition did not affect the number of cells transfected with peptide-based gene transfer agents, but increased the amount of protein made per cell (4).

Proteasome inhibitors have been shown to increase AAV-mediated transduction in C57B1/6 mice and Rag-deficient mice (2;11). Here, we show that proteasome inhibitors increase lipid-mediated gene transfer in a variety of strains including wild type Balb/C mice, C57B1/6 mice and gut-corrected CF knockout mice on a mixed 
genetic background. Thus, the drug action appears to be strain- and CF genotype independent. By spiking homogenized lung tissue with Dox immediately before performing a luciferase assay we excluded a direct effect of the drug on photon emission (data not shown).

We also show that Dox pretreatment improved in vivo bioluminescence imaging (BLI) of reporter gene expression after nebulisation of GL67A/DNA complexes to the mouse lung. The whole body nebulisation set-up used in the study is comparatively inefficient in delivering gene transfer agents to the murine lung and it was, therefore, not surprising that photon emission was too low to generate a visible BLI signal in most animals after IP injection of luciferin substrate. Importantly, however, topical administration of luciferin directly to the lung increased photon emission significantly and generated a BLI signal in 7 out of 9 mice despite the fact that only half of the dose recommended for IP injections was delivered. Not surprisingly a combination of luciferin administration directly to the lung and doxorubicin pre-treatment further increased photon emission. The enhanced photon emission after topical administration of luciferin is likely due to a higher local concentration of the substrate in transfected lung epithelium. Buckley et al have shown that topical administration of luciferin also increased lung photon emission after virus-mediated gene transfer (16). More extensive dose-optimisation may significantly reduce the amount of luciferin required and, thereby, reduce costs of BLI studies.

Although it is generally assumed and probably most plausible that the beneficial effects of doxorubicin on viral and non-viral gene transfer are due to proteasome inhibition, it is worth mentioning that doxorubicin has additional effect. The drug 
intercalates into DNA and inhibits topisomerase II activity (17) and the implications of these actions on gene expression after gene transfer are not understood. Importantly, we show that the drug action is promoter/enhancer-independent as doxorubicin increased CMV and elongation factor $1 \alpha$ (hCEFI)-dependent gene expression. Doxorubicin is also known to activate reactive oxygen species (ROS) and one conceivable explanation may be that ROS activate the transcription factor NFкB. $(18 ; 19)$

A more advanced pegylated liposomal formulation of the first-generation doxorubicin is currently in clinical use. The coating prolongs the circulating half-life and slows down plasma clearance compared to free doxorubicin, but most importantly leads to preferential accumulation in tumors, thereby reducing systemic toxicity (20) respectively. We also assessed the effects of Caelyx ${ }^{\circledR}$ IP administration on airway gene transfer, but did not detect any changes in gene expression. Clinically Caelyx ${ }^{\circledR}$ is administered intravenously and, therefore, we assessed its effects via this route of delivery. Although there was a modest increase in lung gene expression, this did not reach significance. These results are perhaps unsurprising given that the formulation was developed for accumulation in tumours. Caelyx ${ }^{\circledR}$ liposomes have an average diameter of approximately $100 \mathrm{~nm}$ able to penetrate the discontinuous endothelium of tumour vasculature, but not other tissues (21). Thus, the drug may not have reached the airway epithelium in sufficiently high concentrations. In contrast Yan et al showed that IV administration of Doxil ${ }^{\circledR}$, a formulation identical to Caelyx ${ }^{\circledR}$, increased AAVmediated gene expression in a murine tracheal xenograft model (11). The newly formed vasculature supplying the xenograft may be more discontinuous than the 
Uta Griesenbach July 2008

vasculature in the in vivo lung, thereby allowing for drug delivery to the target epithelium.

\section{Conclusions}

As for AAV-mediated gene transfer, doxorubicin increased lipid-mediated gene transfer to the murine lung. The clinically relevant agent doxorubicin shows a narrow efficacy-toxicity window, which was not improved by variations in route of administration. We conclude that although it may be unlikely that Dox will be suitable for clinically relevant gene therapy in CF patients an understanding on how the drug increases lung gene expression may help to shed light on intracellular bottle-necks to gene transfer, and may help to identify other adjuncts which may be more appropriate for use in humans. 
Uta Griesenbach July 2008

\section{Acknowledgements}

Ronald Scheule and Seng Cheng declare they are employees and shareholders of

Genzyme Corporation, no other conflicts of interest exist. We thank Luci Somerton for help with preparing the manuscript. This work was funded by the Cystic Fibrosis Trust and the Dr Benjamin Angel Senior Lectureship (Uta Griesenbach). 


\section{References}

(1) Ding W, Yan Z, Zak R, Saavedra M, Rodman DM, Engelhardt JF. Secondstrand genome conversion of adeno-associated virus type $2(\mathrm{AAV}-2)$ and AAV-5 is not rate limiting following apical infection of polarized human airway epithelia. J Virol 2003 Jul;77(13):7361-6.

(2) Yan Z, Lei-Butters DC, Zhang Y, Zak R, Engelhardt JF. Hybrid adenoassociated virus bearing nonhomologous inverted terminal repeats enhances dual-vector reconstruction of minigenes in vivo. Hum Gene Ther 2007 Jan;18(1):81-7.

(3) Zhang LN, Karp P, Gerard CJ, Pastor E, Laux D, Munson K, et al. Dual therapeutic utility of proteasome modulating agents for pharmaco-gene therapy of the cystic fibrosis airway. Mol Ther 2004 Dec;10(6):990-1002.

(4) Kim J, Chen CP, Rice KG. The proteasome metabolizes peptide-mediated nonviral gene delivery systems. Gene Ther 2005 Nov;12(21):1581-90.

(5) Kim KI, Kang JH, Chung JK, Lee YJ, Jeong JM, Lee DS, et al. Doxorubicin enhances the expression of transgene under control of the CMV promoter in anaplastic thyroid carcinoma cells. J Nucl Med 2007 Sep;48(9):1553-61.

(6) Harvey BG, Leopold PL, Hackett NR, Grasso TM, Williams PM, Tucker AL, et al. Airway epithelial CFTR mRNA expression in cystic fibrosis patients after repetitive administration of a recombinant adenovirus. J Clin Invest 1999 Nov;104(9):1245-55.

(7) Sumner-Jones SG, Gill DR, Hyde SC. Lack of repeat transduction by recombinant adeno-associated virus type $5 / 5$ vectors in the mouse airway. $\mathrm{J}$ Virol 2007 Nov;81(22):12360-7.

(8) Lee ER, Marshall J, Siegel CS, Jiang C, Yew NS, Nichols MR, et al. Detailed analysis of structures and formulations of cationic lipids for efficient gene transfer to the lung. Hum Gene Ther 1996 Sep 10;7(14):1701-17.

(9) Alton EW, Stern M, Farley R, Jaffe A, Chadwick SL, Phillips J, et al. Cationic lipid-mediated CFTR gene transfer to the lungs and nose of patients with cystic fibrosis: a double-blind placebo-controlled trial. Lancet $1999 \mathrm{Mar}$ 20;353(9157):947-54.

(10) Yonemitsu Y, Kitson C, Ferrari S, Farley R, Griesenbach U, Judd D, et al. Efficient gene transfer to airway epithelium using recombinant Sendai virus. Nat Biotechnol 2000 Sep;18(9):970-3.

(11) Yan Z, Zak R, Zhang Y, Ding W, Godwin S, Munson K, et al. Distinct classes of proteasome-modulating agents cooperatively augment recombinant adenoassociated virus type 2 and type 5-mediated transduction from the apical surfaces of human airway epithelia. J Virol 2004 Mar;78(6):2863-74. 
(12) Kunzelmann K, Schwiebert EM, Zeitlin PL, Kuo WL, Stanton BA, Gruenert DC. An immortalized cystic fibrosis tracheal epithelial cell line homozygous for the delta F508 CFTR mutation. Am J Respir Cell Mol Biol 1993 May;8(5):522-9.

(13) Zhou L, Dey CR, Wert SE, DuVall MD, Frizzell RA, Whitsett JA. Correction of lethal intestinal defect in a mouse model of cystic fibrosis by human CFTR. Science 1994 Dec 9;266(5191):1705-8.

(14) Hyde SC, Pringle IA, Abdullah S, Lawton AE, Davies LA, Varathalingam A, et al. CpG-free plasmids confer reduced inflammation and sustained pulmonary gene expression. Nat Biotechnol 2008 May;26(5):549-51.

(15) Griesenbach U, Meng C, Farley R, Cheng SH, Scheule RK, Davies MH, et al. In vivo imaging of gene transfer to the respiratory tract. Biomaterials 2008 Apr;29(10):1533-40.

(16) Buckley SM, Howe SJ, Wong SP, Buning H, McIntosh J, Baker A, et al. Luciferin detection after intra-nasal vector delivery is improved by intra-nasal rather than intra-peritoneal luciferin administration. Hum Gene Ther 2008 Aug 14.

(17) Binaschi M, Bigioni M, Cipollone A, Rossi C, Goso C, Maggi CA, et al. Anthracyclines: selected new developments. Curr Med Chem Anticancer Agents 2001 Aug;1(2):113-30.

(18) Chen JJ, Chou CW, Chang YF, Chen CC. Proteasome Inhibitors Enhance TRAIL-Induced Apoptosis through the Intronic Regulation of DR5: Involvement of NF- $\{$ kappa $\}$ B and Reactive Oxygen Species-Mediated p53 Activation. J Immunol 2008 Jun 15;180(12):8030-9.

(19) Takemura G, Fujiwara H. Doxorubicin-induced cardiomyopathy from the cardiotoxic mechanisms to management. Prog Cardiovasc Dis 2007 Mar;49(5):330-52.

(20) Tejada-Berges T, Granai CO, Gordinier M, Gajewski W. Caelyx/Doxil for the treatment of metastatic ovarian and breast cancer. Expert Rev Anticancer Ther 2002 Apr;2(2):143-50.

(21) Charrois GJ, Allen TM. Rate of biodistribution of STEALTH liposomes to tumor and skin: influence of liposome diameter and implications for toxicity and therapeutic activity. Biochim Biophys Acta 2003 Jan 10;1609(1):102-8. 